\title{
Excretion of urine extracellular vesicles bearing markers of activated immune cells and calcium/phosphorus physiology differ between calcium kidney stone formers and non-stone formers
}

Jiqing Zhang ${ }^{1,2}$, Sanjay Kumar ${ }^{2,3}$, Muthuvel Jayachandran ${ }^{2,4,5}$, Loren P. Herrera Hernandez ${ }^{6}$, Stanley Wang ${ }^{2}$, Elena M. Wilson ${ }^{2}$ and John C. Lieske ${ }^{2,6^{*}}$

\begin{abstract}
Backgrounds:: Previous studies have demonstrated that excretion of urinary extracellular vesicles (EVs) from different nephron segments differs between kidney stone formers and non-stone formers (NSFs), and could reflect pathogenic mechanisms of urinary stone disease. In this study we quantified selected populations of specific urinary EVs carrying protein markers of immune cells and calcium/phosphorus physiology in calcium oxalate stone formers (CSFs) compared to non-stone formers (NSFs).

Methods: Biobanked urine samples from CSFs $(n=24)$ undergoing stone removal surgery and age- and sexmatched NSFs $(n=21)$ were studied. Urinary EVs carrying proteins related to renal calcium/phosphorus physiology (phosphorus transporters (PiT1 and PiT2), Klotho, and fibroblast growth factor 23 (FGF23); markers associated with EV generation (anoctamin-4 (ANO4) and Huntington interacting protein 1 (HIP1)), and markers shed from activated immune cells were quantified by standardized and published method of digital flow cytometry.
\end{abstract}

\footnotetext{
* Correspondence: lieske.john@mayo.edu

${ }^{2}$ Department of Internal Medicine, Division of Nephrology and Hypertension,

Mayo Clinic, 200 First Street SW, MN 55905 Rochester, USA

${ }^{6}$ Department of Laboratory Medicine and Pathology, Mayo Clinic, 55905

Rochester, MN, USA

Full list of author information is available at the end of the article
}

(c) The Author(s). 2021 Open Access This article is licensed under a Creative Commons Attribution 4.0 International License, which permits use, sharing, adaptation, distribution and reproduction in any medium or format, as long as you give appropriate credit to the original author(s) and the source, provide a link to the Creative Commons licence, and indicate if changes were made. The images or other third party material in this article are included in the article's Creative Commons licence, unless indicated otherwise in a credit line to the material. If material is not included in the article's Creative Commons licence and your intended use is not permitted by statutory regulation or exceeds the permitted use, you will need to obtain permission directly from the copyright holder. To view a copy of this licence, visit http://creativecommons.org/licenses/by/4.0/. The Creative Commons Public Domain Dedication waiver (http://creativecommons.org/publicdomain/zero/1.0/) applies to the data made available in this article, unless otherwise stated in a credit line to the data. 


\begin{abstract}
Results: Urine excretion of calcium, oxalate, phosphorus, and calcium oxalate supersaturation (SS) were significantly higher in CSFs compared to NSFs $(P<0.05)$. Urinary excretion of EVs with markers of total leukocytes $(C D 45)$, neutrophils (CD15), macrophages (CD68), Klotho, FGF23, PiT1, PiT2, and ANO4 were each markedly lower in CSFs than NSFs $(P<0.05)$ whereas excretion of those with markers of monocytes (CD14), T-Lymphocytes (CD3), BLymphocytes (CD19), plasma cells (CD138 plus CD319 positive) were not different between the groups. Urinary excretion of EVs expressing PiT1 and PiT2 negatively $(P<0.05)$ correlated with urinary phosphorus excretion, whereas excretion of EVs expressing FGF23 negatively $(P<0.05)$ correlated with both urinary calcium and phosphorus excretion. Urinary EVs with markers of HIP1 and ANO4 correlated negatively $(P<0.05)$ with clinical stone events and basement membrane calcifications on papillary tip biopsies.

Conclusions: Urinary excretion of EVs derived from specific types of activated immune cells and EVs with proteins related to calcium/phosphorus regulation differed between CSFs and NSFs. Further validation of these and other populations of urinary EVs in larger cohort could identify biomarkers that elucidate novel pathogenic mechanisms of calcium stone formation in specific subsets of patients.
\end{abstract}

Keywords: Calcium, Oxalate, Urinary extracellular vesicles, Inflammation, Phosphorus, Urinary stone disease

\section{Background}

Urinary stone disease (USD) is common, painful, and costly to manage, affecting approximately 1 in 11 people in the United States and $5-15 \%$ of the population worldwide[1-3]. Management of USD constitutes a significant portion of the patient load in urology clinics[4]. The majority $(70-80 \%)$ of urinary stones are composed of calcium oxalate $(\mathrm{CaOx})$, often in combination with calcium phosphate[5].The 5 year recurrence rate after a first USD event can be as high as $50 \%[6]$. Many stones, especially idiopathic $\mathrm{CaOx}$ stones, appear to arise from subepithelial inner medullary calcium phosphate $(\mathrm{CaP})$ crystal deposits called Randall's plaques (RP) $[2,7,8]$. These interstitial apatite deposits appear to originate in basement membrane zones of the thin limb of Henle's loop, and over time extend along the basement membrane of the thin limb to create apatite plaques beneath the papillary epithelium[7-10]. The plaques eventually breach the surface epithelium of renal papillae and extrude into the urinary space[2, 9, 10]. Once exposed, $\mathrm{RP}$ appear to serve as a nidus for deposition of protein and crystal layers from the urine in the renal pelvis, thus ultimately leading to anchored $\mathrm{CaP}$ and/or $\mathrm{CaOx}$ urinary stones[2, $8,9]$.However, much is still not clear about the initiation and progression of RP and calcium stone formation. This lack of an in-depth mechanistic understanding has hindered the development of potential therapies [5].

Supersaturation within tubular fluid favors $\mathrm{CaOx}$ crystal formation. Once formed these crystals may adhere to and become internalized by tubular epithelial cells, and subsequently transmigrate into the interstitium[11]. These, crystals may activate interstitial mononuclear phagocytes including dendritic cells and macrophages that can release cytokines including interleukin-1 $\beta$ (IL$1 \beta)$ to promote inflammatory cell transmigration and recruitment to the site of inflammation[11, 12]. Activation of nicotinamide adenine dinucleotide phosphate (NADP $\mathrm{H}$ ), leucine-rich repeat (LRR), and NOD like pyrin domain-containing protein 3 (NLRP3) in macrophages can potentially aid in crystal dissolution, and in vitro studies suggest that $\mathrm{CaOx}$ crystals up to $200 \mu \mathrm{m}$ in size can be dissolved within 3 days[7, 11]. NLRP3 serves as a marker of inflammasome activation, a process that promotes immune cell influx and triggers vascular permeability, leukocyte recruitment, complement activation, and inflammatory mediator production[13].

Extracellular vesicles (EVs) are lipid bilayer membrane-bound vesicles secreted by almost all cells involved in pathophysiological processes[12, 14]. EVs appear to transmit signals between cells under both physiological and pathological conditions[14]. The concentration and content of bioactive molecules in urinary EVs, including microRNA, DNA, mRNA, lipids and proteins all depend on their cell of origin and/or stimulus for their secretion [14-16]. Previous studies have reported that EVs participate in signal communication during renal regenerative and pathological processes[14]. Thus, specific populations of urinary EVs may reflect pathophysiological processes within the kidney[15]. In particular, urinary EVs released from the epithelium of different nephron segments could serve as biomarkers of diverse pathological states and response to therapeutic agents[5]. Previous reports demonstrated that EVs derived from specific immune cells and EVs carrying innate immune proteins can be detected in the urine after kidney transplantation[17, 18].Thus, in the present study we characterized populations of urinary EVs derived from activated immune cells in CSFs compared to NSFs (controls). Our previous studies demonstrated that urinary excretion of specific EV populations derived from different nephron segments varied between cohorts of 
CSFs and NSFs[5, 19].Specifically we quantified urinary EVs bearing markers of immune/inflammatory cells activation, calcium/phosphorus physiology and EV generation from the plasma membrane and endocytic vesicles.

\section{Methods}

Urine sample collection and storage

This study was approved by the Institutional Review Board at the Mayo Clinic, Rochester, MN. CSFs were recruited at the time of percutaneous nephrolithotomy (PCNL) for stone removal. Those CSFs with majority calcium oxalate stones and without secondary causes including hyperparathyroidism or enteric hyperoxaluria were included in the current study. All CSFs had preoperative stone protocol CT examinations available for review. Age- and sex- matched NSFs were recruited from the community lacked history of a clinical kidney stone event, but did not have imaging to exclude asymptomatic stones. Renal papillary surface area affected by $\mathrm{RP}$ was assessed via ureteroscopic video mapping at the time of percutaneous stone removal followed by quantitative image processing as described previously $[9,10,20]$. A papillary tip biopsy was obtained from a representative calyx at the time of mapping as previously described for 17 of the CSFs in the current study [21]. Hematoxylin and eosin and Yasue stained sections of the biopsies were semi quantitatively scored for the presence of intraluminal crystals, basement membrane crystals and interstitial inflammation by a renal pathologist (LPH) blinded to the clinical data. Urine samples (24-hr) were collected in toluene preservative from CSFs ( $\mathrm{n}=24,15$ males and 9 females) with low $(<5 \%$ papillary surface area; $n=16,8$ males and 8 females) and high ( $\geq 5 \%$ papillary surface area; $n=8,7$ males and 1 female ) amounts of RP as determined at the time of urologic stone removal surgery, and from age-/sex-matched non-stone formers (NSFs; controls) in the general population $(n=21 ; 10$ males and 11 females), as previously described [10, 21]. Urine from CSFs was collected a minimum of 6 weeks after the surgical procedure. Urine aliquots were centrifuged (2100 $g$ for $10 \mathrm{~min}$ ) to remove urinary cells and larger protein aggregates prior to freezing at $-80{ }^{\circ} \mathrm{C}$ for EV analysis. Urine biochemistries of the 24-hr urine samples were performed at the Mayo Clinic Renal Testing Laboratory using standard protocols as previously described [21].

\section{Chemicals, reagents, and antibodies}

Recombinant annexin-V (microvesicle marker) and mouse anti-human cluster of differentiation 3 (CD3; marker of T-lymphocyte), CD14 (monocyte marker), CD15 (neutrophil marker), CD19 (B-lymphocyte marker), CD45 (total leukocytes marker), CD68 (macrophage marker), and CD138 (plasma cell marker) antibodies conjugated with fluorescein isothiocyanate (FITC) or R-phycoerythrin (PE) and TruCOUNT ${ }^{\mathrm{Tm}}$ $(4.2 \mu \mathrm{m})$ beads were purchased from BD Biosciences,
San Jose, CA. Mouse anti-human CD319 (marker of plasma cell) antibody was purchased from BioLegend, San Diego, CA. FITC conjugated rabbit anti-human fibroblast growth factor 23 (FGF23) antibody was obtained from Biorbyt, Cambridge, Cambridgeshire, UK. PE conjugated rabbit anti-human Huntington interacting protein 1 (HIP1), anti-human SLC20A1 (phosphate transporter 1; PiT1), anti-human SLC20A2 (phosphate transporter 2; PiT2), and anti-human Klotho antibodies were from Lifespan Biosciences, Inc. Seattle, WA. FITC conjugated rabbit anti-human anoctamin-4 (ANO4) antibody was obtained from United States Biological, Salem, MA. HEPES (4-(2-hydroxyethyl)-1-piperazineethanesulfonic acid), and Hanks balanced salts were purchased from Sigma Chemicals, St. Louis, MO. All reagents and solvents used in this study were of analytical/ reagent grade.

\section{Quantification of urinary EVs by flow cytometry}

A standardized and validated flow cytometry (BD FACS Canto $^{\mathrm{Tx}}$ ) method was used to define EVs by size ( $\geq$ $200 \mathrm{~nm}$ to $\leq 1000 \mathrm{~nm}$ ) and annexin-V-fluorescence for quantification of selected surface biomarker carrying urinary EVs as previously described in detail[5, 15, 16].The absolute number of urinary EVs positive for selected specific biomarkers is reported as both the number of EVs per $\mu \mathrm{L}$ of urine and also normalized to 24-hr urine creatinine concentration[5]. Normalization to urinary creatinine was used to account for the varied concentration of the timed urine collections[22].

\section{Statistical analysis}

Continuous variables were expressed as the median, 25th and 75th percentile. The Wilcoxon rank sum test was used to identify significant differences between groups for continuous variables. Correlations between specific urinary EV populations and urinary phosphorus or calcium excretion was assessed using Spearman's rank correlation coefficient. Nominal and categorical variables were compared using a chi-squared likelihood ratio or Fisher's exact test. $\mathrm{P}<0.05$ was accepted as statistically significant. JMP Pro 13 statistical software (SAS Institute; Cary, NC) was used for all statistical analysis.

\section{Results}

Analysis of clinical characteristics

All stones removed from CSFs at PCNL were composed of a majority calcium oxalate. CSFs had a (median $(25 \%$, $75 \%))$ of $2(1,5)$ clinical stone events and $4(1,7)$ stones on preoperative imaging. There was no significant difference found in age, sex distribution, body mass index, and systolic/diastolic blood pressure between the CSFs and NSFs groups, or between the high and low RP-CSF patients among CSFs (Table 1). Urine $\mathrm{pH}$ in CSFs was 
markedly lower than NSFs $(P<0.05)$, whereas, as expected, urine calcium, oxalate, creatinine, phosphorus, and $\mathrm{CaOx}$ supersaturation (SS) were significantly higher in CSFs than NSFs $(P<0.05)$. By papillary tip mapping, 8 CSF had high ( $\geq 5 \%)$ RP and 16 low $(<5 \%)$ RP. Urine $\mathrm{pH}$ was significantly lower in high RPCSFs than NSFs and low RP-CSFs $(P<0.05)$.Urine calcium was significantly higher in high RP-CSFs than
NSFs $(P<0.05)$, but there was no difference between low RP-CSFs and NSFs (Table 1 ).

Total number of urinary EVs from activated immune/ inflammatory cells

Urinary EVs derived from total leukocytes (CD45), neutrophils (CD15), and macrophages (CD68) were reduced in CSFs compared to NSFs $(P<0.05$, Table 2 and

Table 1 Preoperative patient characteristics and 24-hours urine metabolic profile

\begin{tabular}{|c|c|c|c|c|}
\hline Variables & $\begin{array}{l}\text { NSF } \\
(n=21)\end{array}$ & High RP CSF $(n=8)$ & Low RP CSF $(n=16)$ & $\begin{array}{l}\text { CSF } \\
(\text { High + Low RP), }(n=24)\end{array}$ \\
\hline Age (years) & $\begin{array}{l}65.5 \\
(57.4,73.0)\end{array}$ & $\begin{array}{l}69.2 \\
(60.4,72.2)\end{array}$ & $\begin{array}{l}61.2 \\
(50.1,72.9)\end{array}$ & $\begin{array}{l}63.9 \\
(57.1,72.2)\end{array}$ \\
\hline \multirow[t]{3}{*}{ Sex n (\%) } & $10(47.6 \%)$ & $7(87.5 \%)$ & $8(50 \%)$ & $15(62.5 \%)$ \\
\hline & $11(52.4 \%)$ & $1(12.5 \%)$ & $8(50 \%)$ & $9(37.5 \%)$ \\
\hline & $\begin{array}{l}26.2 \\
(24.5,30.5)\end{array}$ & $\begin{array}{l}30.5 \\
(24.3,34.9)\end{array}$ & $\begin{array}{l}27.7 \\
(24.4,30.0)\end{array}$ & $\begin{array}{l}28.7 \\
(24.4,32.4)\end{array}$ \\
\hline Systolic Blood Pressure (mmHg) & $\begin{array}{l}124 \\
(116.0,137.5)\end{array}$ & $\begin{array}{l}130.5 \\
(112.3,133.5)\end{array}$ & $\begin{array}{l}119 \\
(114,137.8)\end{array}$ & $\begin{array}{l}126 \\
(114,136.8)\end{array}$ \\
\hline Diastolic Blood Pressure (mmHg) & $\begin{array}{l}72 \\
(64.0,82.0)\end{array}$ & $\begin{array}{l}72 \\
(62.0,82.3)\end{array}$ & $\begin{array}{l}69.5 \\
(62.0,77.0)\end{array}$ & $\begin{array}{l}70 \\
(62.0,77.8)\end{array}$ \\
\hline Urine $\mathrm{pH}$ & $\begin{array}{l}6.4 \\
(6.0,7.0)\end{array}$ & $\begin{array}{l}5.5^{\mathrm{a}} \\
(5.2,5.6)\end{array}$ & $\begin{array}{l}6.2^{\mathrm{b}} \\
(5.7,6.5)\end{array}$ & $\begin{array}{l}6.0^{c} \\
(5.4,6.3)\end{array}$ \\
\hline Urine calcium (mg/24hr) & $\begin{array}{l}158.3 \\
(86.4,192.3)\end{array}$ & $\begin{array}{l}255.5^{a} \\
(132.5,406.0)\end{array}$ & $\begin{array}{l}186.5 \\
(103.2,273.2)\end{array}$ & $\begin{array}{l}207.5^{c} \\
(110.8,330.0)\end{array}$ \\
\hline Urine oxalate (mmol/24hr) & $\begin{array}{l}0.27 \\
(0.22,0.35)\end{array}$ & $\begin{array}{l}0.41^{a, b} \\
(0.28,0.64)\end{array}$ & $\begin{array}{l}0.28 \\
(0.22,0.36)\end{array}$ & $\begin{array}{l}0.30^{c} \\
(0.25,0.48)\end{array}$ \\
\hline Urine chloride (mmol/24hr) & $\begin{array}{l}113.8 \\
(73.4,139.7)\end{array}$ & $\begin{array}{l}170.5^{\mathrm{a}} \\
(121.8,233.3)\end{array}$ & $\begin{array}{l}107^{\mathrm{b}} \\
(78.0,153.8)\end{array}$ & $\begin{array}{l}117.8 \\
(99.6,189.3)\end{array}$ \\
\hline Urine citrate (mg/24hr) & $\begin{array}{l}625.3 \\
(331.3,756.8)\end{array}$ & $\begin{array}{l}298.5 \\
(206.3,805.1)\end{array}$ & $\begin{array}{l}557 \\
(231.7,690.5)\end{array}$ & $\begin{array}{l}450.2 \\
(218.8,690.5)\end{array}$ \\
\hline Urine creatinine (mg/24hr) & $\begin{array}{l}869.2 \\
(633.1,1067.3)\end{array}$ & $\begin{array}{l}1790.5^{\mathrm{a}} \\
(1583,2060)\end{array}$ & $\begin{array}{l}1068^{b} \\
(844.3,1451.5)\end{array}$ & $\begin{array}{l}1384.1^{c} \\
(904.8,1647.3)\end{array}$ \\
\hline Urine osmolality (mOsm/kg) & $\begin{array}{l}458 \\
(314.5,731.5)\end{array}$ & $\begin{array}{l}494 \\
(126.3,687)\end{array}$ & $\begin{array}{l}363 \\
(319.5,472.8)\end{array}$ & $\begin{array}{l}392.5 \\
(319.5,556.8)\end{array}$ \\
\hline Urine phosphorus (mg/24hr) & $\begin{array}{l}516.3 \\
(371.5,759.9)\end{array}$ & $\begin{array}{l}1204.5^{a} \\
(1030,1575.3)\end{array}$ & $\begin{array}{l}747.8^{b} \\
(483.1,1008.3)\end{array}$ & $\begin{array}{l}913.5^{c} \\
(525.3,1169.6)\end{array}$ \\
\hline Urine potassium (mmol/24hr) & $\begin{array}{l}48.7 \\
(36.7,76.0)\end{array}$ & $\begin{array}{l}80.5 \\
(59.3,86.8)\end{array}$ & $\begin{array}{l}45.4 \\
(33.1,66.8)^{b}\end{array}$ & $\begin{array}{l}59.5 \\
(36.4,78.8)\end{array}$ \\
\hline Urine sodium (mmol/24hr) & $\begin{array}{l}116.3 \\
(72.1,155.1)\end{array}$ & $\begin{array}{l}174^{a} \\
(131.5,257.5)\end{array}$ & $\begin{array}{l}118.5^{\mathrm{b}} \\
(91,191.8)\end{array}$ & $\begin{array}{l}144.5 \\
(106.3,215.7)\end{array}$ \\
\hline Urine sulfate (mmol/24hr) & $\begin{array}{l}15.4 \\
(11.3,27.5)\end{array}$ & $\begin{array}{l}25 \\
(12,34)\end{array}$ & $\begin{array}{l}11 \\
(9,24)\end{array}$ & $\begin{array}{l}21.5 \\
(10.3,27.3)\end{array}$ \\
\hline Urine volume (ml, 24 h) & $\begin{array}{l}2087 \\
(1597,2529)\end{array}$ & $\begin{array}{l}2388 \\
(1596,3222)\end{array}$ & $\begin{array}{l}2095 \\
(1454,2788)\end{array}$ & $\begin{array}{l}2115 \\
(1454,3064)\end{array}$ \\
\hline Urine calcium phosphate-brushite SS (DG) & $\begin{array}{l}-0.8 \\
(-1.7,0.4)\end{array}$ & $\begin{array}{l}-1.7 \\
(-2.0,0.1)\end{array}$ & $\begin{array}{l}-0.1 \\
(-1.7,0.8)\end{array}$ & $\begin{array}{l}-0.34 \\
(-2.0,0.6)\end{array}$ \\
\hline Urine calcium oxalate SS (DG) & $\begin{array}{l}1.1 \\
(0.7,1.6)\end{array}$ & $\begin{array}{l}1.8 \\
(1.2 .2 .5)\end{array}$ & $\begin{array}{l}1.6 \\
(1.1,2.3)\end{array}$ & $\begin{array}{l}1.6^{c} \\
(1.1,2.3)\end{array}$ \\
\hline
\end{tabular}

Data are presented as median (25th and 75th percentile)

$P$ values in bold denote significance at $<0.05$ level

Abbreviations: CSF calcium stone formers; DG delta Gibbs; NSF non-stone formers; SS supersaturation ${ }^{\text {a }}$ Significant difference between high RP CSF and NSFs

bSignificant difference between high RP and low RP CSF

'Significant difference between CSFs and NSFs 
Supplemental Figure 1), while excretions of EVs from activated T-lymphocytes (CD3),B-lymphocytes (CD19), monocytes (CD14)and plasma cells (CD138 plus CD319 positive) were not statistically different between CSFs and NSFs (Table 2).The number of total leukocyte (CD45) positive urinary EVs in high and low RP-CSF patients was lower than NSFs $(P<0.05)$. Urinary excretion of EVs bearing markers of immune cells did not statistically differ between high and low RP-CSFs (Table 2). In all cases, relative differences in the population of EVs were the same when expressed as EVs/ $/$ l (Supplemental Table 1).

\section{Urinary EVs expressing biomarkers of plasma membrane vesicle generation (anoctamin 4;ANO4) and endocytosis mediated exosome generation (Huntington interacting protein 1;HIP1)}

Urinary excretion of ANO4 expressing EVs was significantly lower in CSFs than NSFs $(P<0.05)$, while EVs expressing HIP1 trended lower in CSFs compared to NSFs $(P=0.07$, Table 3 and Supplemental Figure 2). There were no marked differences in the urinary excretion of EVs carrying HIP1 and ANO4 between low and high RP-CSF groups (Table 3). In all cases, relative differences in the population of EVs were the same when expressed as EVs/ $\mu$ l (Supplemental Table 2).

\section{Urinary EVs expressing calcium/phosphorus physiology}

Urinary excretions of EVs positive for FGF23, Klotho, PiT1, and PiT2 were significantly $(P<0.05)$ lower in CSFs compared to NSFs (Table 3 and Supplemental Figure 2).Urinary excretion of FGF23- carrying EVs in high RP-CSFs was significantly lower than NSFs $(P<0.05)$, while there was no significant difference between low RP-CSFs and NSFs (Table 3). In all cases, relative differences in the population of EVs were the same when expressed as EVs/ $\mu \mathrm{l}$ (Supplemental Table 1). The number of PiT1 positive urinary EVs in high and low RPCSF patients was lower than NSFs $(P<0.05)$. Urinary excretion of Klotho positive EVs were reduced in low RPCSFs compared with NSFs $(P<0.05)$. There was no significant difference observed between high RP-CSF and low RP-CSF for PiT1, PiT2, FGF23 and Klotho (Table 3). Urinary excretion of EVs bearing PiT1 $(\rho=-0.35 ; P<0.05)$ and PiT2 $(\rho=-0.36 ; P<0.05)$ negatively correlated with 24-hr urine phosphorus excretion (Table 4), while excretion of EVs bearing FGF23 negatively correlated with 24-hr urine phosphorus $(\rho=-0.34 ; P<0.05$, Table 4$)$ and calcium $(\rho=-0.29 ; P<0.05$, Table 5$)$.

In an exploratory analysis, the association of urinary EV populations with clinical stone events, stones on imaging, and papillary tip histology was examined (Table 6). Urinary EVs bearing HIP1 and ANO4 negatively $(P<$ $0.05)$ correlated with clinical stones and basement membrane crystallization, while those bearing PiT1, PiT2, and Klotho negatively $(P<0.05)$ correlated with basement membrane crystallization. Urinary EVs bearing CD19 correlated positively with intraluminal crystals and interstitial inflammation.

\section{Discussion}

In the current study, we quantified specific populations of EVs in the urine of CSFs compared to NSFs. Results indicate that the number of EVs carrying immune/inflammatory cell markers including those of leukocytes, neutrophils, and macrophages were lower in CSFs compared to NSFs. In addition, the number of EVs bearing markers of proteins important in calcium and phosphorus regulation including FGF23, PiT1, PiT2, and

Table 2 Urinary excretion of EVs carrying biomarkers of immune/ inflammatory cells in CSFs and NSFs

\begin{tabular}{|c|c|c|c|c|c|}
\hline Urinary EVs/ mg creatinine & Marker & $\begin{array}{l}\text { NSF } \\
(n=21)\end{array}$ & $\begin{array}{l}\text { High RP CSF } \\
(n=8)\end{array}$ & Low RP CSF $(n=16)$ & $\begin{array}{l}\text { CSF } \\
\text { (High + Low RP) }(n=24)\end{array}$ \\
\hline Total leukocyte & $\mathrm{CD} 45$ & $\begin{array}{l}10.5 \\
(10.2,11.9)\end{array}$ & $\begin{array}{l}10.1^{\mathrm{a}} \\
(9.4,10.3)\end{array}$ & $\begin{array}{l}10.1^{\mathrm{b}} \\
(9.5,10.7)\end{array}$ & $\begin{array}{l}10.1^{c} \\
(9.5,10.3)\end{array}$ \\
\hline Neutrophil & CD15 & $\begin{array}{l}11.7 \\
(10.8,12.6)\end{array}$ & $\begin{array}{l}10.8 \\
(10.0,11.7)\end{array}$ & $\begin{array}{l}10.8 \\
(10.2,11.5)\end{array}$ & $\begin{array}{l}10.8^{\complement} \\
(10.2,11.5)\end{array}$ \\
\hline B-lymphocyte & CD19 & $\begin{array}{l}11.0 \\
(10.0,12.3)\end{array}$ & $\begin{array}{l}10.0 \\
(9.7,11.2)\end{array}$ & $\begin{array}{l}10.0 \\
(9.7,11.2)\end{array}$ & $\begin{array}{l}10.0 \\
(9.7,11.2)\end{array}$ \\
\hline T-lymphocyte & CD3 & $\begin{array}{l}10.5 \\
(10.1,11.4)\end{array}$ & $\begin{array}{l}10.3 \\
(9.8,10.4)\end{array}$ & $\begin{array}{l}10.2 \\
(9.7,10.5)\end{array}$ & $\begin{array}{l}10.2 \\
(9.8,10.5)\end{array}$ \\
\hline Monocyte & CD14 & $\begin{array}{l}11.4 \\
(10.1,12.3)\end{array}$ & $\begin{array}{l}10.4 \\
(9.7,11.2)\end{array}$ & $\begin{array}{l}10.2 \\
(9.5,11.4)\end{array}$ & $\begin{array}{l}10.3 \\
(9.5,11.2)\end{array}$ \\
\hline Macrophage & CD68 & $\begin{array}{l}10.9 \\
(10.4,12.2)\end{array}$ & $\begin{array}{l}10.0^{\mathrm{a}} \\
(9.5,10.7)\end{array}$ & $\begin{array}{l}10.4 \\
(10.1,10.9)\end{array}$ & $\begin{array}{l}10.3^{\mathrm{C}} \\
(9.8,10.8)\end{array}$ \\
\hline Plasma cell & CD138 + CD319 & $\begin{array}{l}8.9 \\
(7.8,10.6)\end{array}$ & $\begin{array}{l}8.8 \\
(8.3,9.4)\end{array}$ & $\begin{array}{l}8.4 \\
(7.5,9.5)\end{array}$ & $\begin{array}{l}8.7 \\
(7.7,9.5)\end{array}$ \\
\hline
\end{tabular}

Data are presented as median (25th and 75th percentile) of natural log of EVs/mg creatinine. $P$ values in bold denote significance at $<0.05$ level

${ }^{\text {a }}$ Significant difference between high RP-CSF and NSFs

${ }^{b}$ Significant difference between low RP-CSF and NSFs

'Significant difference between CSFs and NSFs 
Table 3 Urinary excretion of EVs carrying biomarkers of calcium and phosphorus physiology in CSFs and NSFs

\begin{tabular}{|c|c|c|c|c|c|}
\hline Urinary EVs/ mg creatinine & Marker & $\begin{array}{l}\text { NSF } \\
(n=21)\end{array}$ & High RP CSF $(n=8)$ & Low RP CSF $(n=16)$ & $\begin{array}{l}\text { CSF } \\
(\text { High + Low RP) }(n=24)\end{array}$ \\
\hline Exosome generation & HIP1 & $\begin{array}{l}11.7 \\
(10.5,12.7)\end{array}$ & $\begin{array}{l}10.6 \\
(10.2,12.1)\end{array}$ & $\begin{array}{l}10.8 \\
(10.5,11.4)\end{array}$ & $\begin{array}{l}10.8 \\
(10.3,11.5)\end{array}$ \\
\hline Microvesicles generation & ANO4 & $\begin{array}{l}12.0 \\
(11.2,13.0)\end{array}$ & $\begin{array}{l}11.2 \\
(10.2,12.6)\end{array}$ & $\begin{array}{l}11.3 \\
(10.6,12.3)\end{array}$ & $\begin{array}{l}11.3^{\complement} \\
(10.5,12.3)\end{array}$ \\
\hline Calcium/phosphorus regulators & FGF23 & $\begin{array}{l}11.5 \\
(10.0,12.0)\end{array}$ & $\begin{array}{l}9.8^{\mathrm{a}} \\
(9.4,11.2)\end{array}$ & $\begin{array}{l}10.4 \\
(9.8,11.0)\end{array}$ & $\begin{array}{l}10.0^{\complement} \\
(9.7,11.0)\end{array}$ \\
\hline Calcium/phosphorus regulators & Klotho & $\begin{array}{l}13.6 \\
(13.0,14.7)\end{array}$ & $\begin{array}{l}12.9 \\
(12.4,14.3)\end{array}$ & $\begin{array}{l}12.5^{\mathrm{b}} \\
(11.6,13.0)\end{array}$ & $\begin{array}{l}12.5^{c} \\
(11.7,13.5)\end{array}$ \\
\hline Phosphate transporter 1 & PiT1 & $\begin{array}{l}12.1 \\
(10.8,13.0)\end{array}$ & $\begin{array}{l}10.5^{\mathrm{a}} \\
(10.2,11.7)\end{array}$ & $\begin{array}{l}10.6^{\mathrm{b}} \\
(10.0,11.6)\end{array}$ & $\begin{array}{l}10.6^{c} \\
(10.1,11.6)\end{array}$ \\
\hline Phosphate transporter 2 & PiT2 & $\begin{array}{l}12.8 \\
(11.6,14.7)\end{array}$ & $\begin{array}{l}11.8 \\
(11.1,13.8)\end{array}$ & $\begin{array}{l}11.6 \\
(10.6,13.0)\end{array}$ & $\begin{array}{l}11.7^{c} \\
(10.9,13.0)\end{array}$ \\
\hline
\end{tabular}

Data are presented as median (25th and 75th percentile) of natural log of EVs/mg creatinine. $P$ values in bold denote significance at $<0.05$ level

${ }^{a}$ Significant difference between high RP-CSF and NSFs

${ }^{b}$ Significant difference between low RP-CSF and NSFs

'Significant difference between CSFs and NSFs

Klotho were also lower in the CSFs compared to NSFs. In general, the number of EVs did not differ between CSFs with high versus low amounts of RP. These results indicate that specific populations of urinary EVs may reflect ongoing pathological events in the kidney of the CSFs, but perhaps those pathways are independent of, or differ in some way, from pathways that resulted in RP formation.

Under normal conditions, nanocrystals can form and grow in tubular fluid, but then pass out as crystalluria[23]. Generally speaking, the literature suggests that on average stone formers excrete a greater number of crystals of larger size[23, 24]. Observations made using cultured cells in vitro, experimental animals in vivo, and kidney tissue from CSFs suggest that $\mathrm{CaOx}$ crystals can adhere to tubular epithelial cells, become transcytosed to the renal interstitium, and undergo dissolution within cells $[8,11,12,25-27]$. The kidney harbors a variety of resident immune cells including macrophages and lymphocytes[28]. CaOx crystal deposition can activate renal immune cells to increase release of chemokines and proinflammatory cytokines, which in turn can recruit additional inflammatory cells including monocytes and neutrophils to the site[11, 12, 28, 29]. EVs secreted by these immune cells can serve as a biomarker of their presence and activation, and may also serve signaling functions in vivo, including antigen presentation, immune suppression, and tissue remodeling[30]. EVs secreted by innate immune cells such as macrophages appear to impact innate immune regulation primarily as pro-inflammatory and paracrine mediators[31]. In contrast, some subsets of immune cells and their signaling molecules can suppress an immune response[13, 32]. For example, neutrophils secrete EVs that have antiinflammatory and immunosuppressive effects, mainly on dendritic cells and macrophages[31].

Although it is assumed that urinary EVs are mainly derived from kidney cells, evidence suggests that circulating exosomes can also enter the urine via trans tubular release[33]. Interestingly, in the current study the number of urinary EVs bearing immune cell markers CD45, CD15, and CD68 were reduced in CSFs compared with NSFs. Previously we had demonstrated that urinary excretion of EVs carrying the inflammatory

Table 4 Correlation between urine EVs carrying markers of EVs generation, calcium and phosphorous regulators and urine phosphorus

\begin{tabular}{lll}
\hline Urinary EV vs. Urine phosphorus correlation & $\begin{array}{l}\text { Spearman's Coefficient } \\
(\boldsymbol{\rho})\end{array}$ & $\boldsymbol{P}$ value \\
\hline Huntington interacting protein 1 (HIP1) & -0.19 & 0.20 \\
Anoctamin 4 (ANO4) & -0.22 & 0.12 \\
Fibroblast growth factor 23 (FGF23) & $-\mathbf{0 . 3 4}$ & $\mathbf{0 . 0 2}$ \\
Klotho & -0.21 & 0.15 \\
Phosphate transporter 1 (PiT1) & $-\mathbf{0 . 3 5}$ & $\mathbf{0 . 0 2}$ \\
Phosphate transporter 2 (PiT2) & $-\mathbf{0 . 3 6}$ & $\mathbf{0 . 0 1}$ \\
\hline
\end{tabular}


Table 5 Correlation between urinary EVs carrying markers of EVs generation, calcium and phosphorous regulators and urine calcium

\begin{tabular}{lll}
\hline Urinary EV vs. urine $\mathrm{Ca}^{++}$correlation & $\begin{array}{l}\text { Spearman's coefficient } \\
(\boldsymbol{\rho})\end{array}$ & $\boldsymbol{P}$ value \\
\hline Huntington interacting protein 1 (HIP1) & 0.04 & 0.78 \\
Anoctamin 4 (ANO4) & 0.10 & 0.49 \\
Fibroblast growth factor 23 (FGF23) & $\mathbf{- 0 . 2 9}$ & $\mathbf{0 . 0 4}$ \\
Klotho & -0.08 & 0.59 \\
Phosphate transporter 1 (PiT1) & -0.17 & 0.26 \\
Phosphate transporter 2 (PiT2) & -0.08 & 0.60 \\
\hline
\end{tabular}

mediator monocyte chemoattractant protein-1 was also lower in CSFs compared to NSFs[16]. Although in the current study sufficient quantities of matching kidney tissue was not available from the CSFs in order to quantitate sub populations of immune/inflammatory cell and correlate that with urinary EV populations, previously published studies do suggest that the number of immune cells within the kidney bearing CD68 may differ in CSFs compared to NSFs[27]. In the current study the number of inflammatory cell-derived EVs did not differ between high RP and low RP-CSFs. This finding is consistent with previous reports that RP is not associated with inflammation[8]. Thus, in this study the observed

Table 6 Correlation between specific populations of urinary extracellular vesicles (EVs), clinical stone events, and papillary tip histology in calcium kidney stone formers

\begin{tabular}{lll}
\hline Urinary EV population & Spearman' correlation $(\boldsymbol{\rho})$ & $P$-value \\
\hline Clinical Stones & & \\
Total Stone Events & & $<0.05$ \\
HIP1 positive EVs & -0.47 & $<0.05$ \\
ANO4 positive EVs & -0.45 & \\
Stones on imagining at the time of surgery & 0.06 \\
HIP1 positive EVs & -0.37 & \\
Papillary Biopsy Findings & & \\
Intraluminal crystals & & $<0.05$ \\
CD19 positive EVs & 0.59 & $<0.05$ \\
Punctate basement membrane crystals & $<0.05$ \\
HIP1 positive EVs & -0.44 & $<0.01$ \\
ANO4 positive EVs & -0.57 & $<0.01$ \\
Klotho positive EVs & -0.55 & $<0.05$ \\
PiT1 positive EVs & -0.52 & \\
PiT2 positive EVs & -0.45 & 0.09 \\
Dense basement membrane staining & \\
ANO4 positive EVs & -0.41 & \\
Interstitial inflammation & & \\
CD19 positive EVs & 0.56 & \\
\hline Only signifanly associated biom &
\end{tabular}

Only significantly associated biomarker-positive urinary EVs are presented. Other biomarker-carrying urinary EVs did not correlate significantly with clinical stone events and papillary tip histology in this cohort of calcium kidney stone formers (data not shown) populations of EVs that differed between CSFs and NSFs likely reflect events involved in stone formation, but that are independent of RP formation and instead may relate to processing of those crystals that are retained in the kidney.

Singhto et al., $[13,29]$ reported that exposure of macrophages to calcium oxalate monohydrate (COM) crystals altered expression of 26 exosome proteins involved in immune signaling. They also demonstrated that exposure of macrophages with exosomes derived from COM-treated macrophages enhanced their COM binding capacity and increased crystal migration through the extracellular matrix[29].These macrophages manifest increased fragility due to actin cytoskeleton alterations[29]. To some extent, these findings may partially explain why in the current study the number of urinary EVs derived from immune cells was lower in CSFs than NSFs; however, further studies are needed to elucidate this mechanism.

In bone and cartilage the transmembrane proteins PiT1 and PiT2 transport inorganic phosphate $\left(\mathrm{P}_{\mathrm{i}}\right)$ into matrix vesicles, promoting nucleation and crystallization of $\mathrm{Ca}^{2+}-\mathrm{PO}_{4}$ [34]. Fibroblast growth factor 23 (FGF23) is produced primarily by osteocytes[35]. FGF23 acts on the proximal tubule to decrease phosphorus reabsorption and reduce serum levels of 1,25-dihydroxyvitamin D3 [1, 25(OH)2 Vitamin D3][35-37].The proximal tubule is responsible for reclaiming the majority of phosphorus filtered from the blood[38]. Klotho is a co-receptor that increases the binding affinity of FGF23 to its receptors[39]. In this study, urinary excretion of EVs carrying all four of these calcium and phosphorus related proteins (FGF23, Klotho, PiT1, and PiT2) were significantly lower in CSFs compared to NSFs. In addition, urinary excretion of FGF23- and PiT1-carrying EVs were significantly lower in high RP-CSFs compared to NSFs. Although the exact mechanisms are not clear, these results suggest that alterations and phosphorus transport in the proximal tubule may influence susceptibility to RP formation.

Urinary EVs are a mixture of exosomes and microvesicles[14]. Exosomes are formed within the endosomal network including early endosomes, late endosomes 
(multivesicular bodies, MVBs), and recycling endosomes[14]. Clathrin has been found in early endosomes, which form from clathrin-coated buds[40]. HIP1 recruits clathrin to endosomes through its central helical domain, which binds directly to highly conserved clathrin light chains (CLCs)[41]. HIP1 binding to CLC is necessary for HIP1 targeting to clathrin-coated pits and clathrin-coated vesicles[41]. Biogenesis of microvesicles occurs via outward budding and fission of the plasma membrane[14]. Anoctamin 4 (ANO4), a $\mathrm{Ca}^{2+}$-dependent phospholipid scramblase, not only takes part in exposing phosphatidylserine from the inner leaflet to the outer leaflet [42, 43], but also alters membrane curvature and facilitates EV release[43]. Thus, HIP1 and ANO4 play essential roles in membrane budding and EV formation and secretion[43]. PiT1 and PiT2 are present in matrix vesicles as noted above. We found that the numbers of EVs carrying plasma membrane EV-biogenesis markers (ANO4) were significantly lower in CSFs compared to NSFs, while the number of EVs carrying HIP1 also trended lower. It is possible that the reduced number of these matrix vesicles relates to their ongoing rupture and calcification within the interstitium of the CSFs.

Differences in the urinary biochemical profile of the CSF versus NSF group in the current study were not surprising, including lower urine $\mathrm{pH}$ and greater calcium and phosphorous excretion and calcium oxalate SS in CSF (Table 1) [4, 16, 27, 44]. Urine calcium and phosphorus excretion in high RP participants were markedly higher compared with NSFs, however those of low RP were not significantly different. Thus, metabolic factors may differ between high versus low RP-CSFs, as we have previously reported[21].We also found that EVs expressing PiT1 and PiT2 were negatively correlated with urinary phosphorus excretion, and urine excretion of EVs expressing FGF23 negatively correlated with urinary calcium and phosphate excretion. Thus, EVs containing FGF23, PiT1, and PiT2 may reflect underlying metabolic features that favor RP formation. However, further study will need to be completed to determine if quantification of EVs expressing PiT1, PiT2 and FGF23 will add additional clinically useful information to traditional urinary super saturation profiles, perhaps reflecting risk for RP and serving as a "liquid biopsy" for USD[5].

Our investigation has some limitations. The sample size is relatively small because we were limited to available biobanked urine samples from surgically mapped CSFs at Mayo Clinic, Rochester, MN. Thus, findings need to be verified in larger cohorts of CSFs. However, the results suggest that urinary EVs differ between CSFs and NSFs may influence directly or indirectly USD pathogenesis.

\section{Conclusions}

In this study we demonstrated that the urinary excretion of EVs carrying immune cell markers including CD45, CD15, and CD68 were lower in CSFs compared to NSFs, but did not differ in the CSFs by RP amount. Excretion of EVs bearing proteins related to renal calcium/phosphorus physiology (FGF23, Klotho, PiT1, and PiT2) were also reduced in CSFs. These differences may reflect ongoing pathogenic events in both low and high RP-CSFs. The cause of the reduced number of these EVs associated with specific biomarkers related to USD risk, and their association with stone pathogenic mechanism(s), needs further study in larger cohorts of CSFs.

\section{Abbreviations}

ANO4: Anoctamin-4; CaOx: Calcium oxalate; CaOx SS: Calcium oxalate Supersaturation; CD: Cluster of differentiation; CLCs: Clathrin light chains; COM: Calcium oxalate monohydrate; CSFs: Calcium stone formers; DG: Delta Gibbs free energy unit; EVs: Extracellular vesicles; FGF23: Fibroblast growth factor 23; FITC: Fluorescein isothiocyanate; HIP1: Huntington interacting protein 1; LRR: Leucine-rich repeat; MCP-1: Monocyte

chemoattractant protein-1; NADPH: Nicotinamide adenine dinucleotide phosphate; NLRP3: NOD like family pyrin domain-containing protein 3; NSFs: Non-stone formers; PE: Phycoerythrin; PiT1: Phosphate transporter 1; PiT2: Phosphate transporter 2

\section{Supplementary Information}

The online version contains supplementary material available at https://doi. org/10.1186/s12882-021-02417-8.

\section{Additional file 1 :}

Additional file 2:

Additional file 3:

Additional file 2:

Additional file 3:

\section{Acknowledgements}

We thank the CSFs and NSFs volunteers for their participation in sample donation for this study. We are grateful to the investigators of the Mayo Clinic Renal Testing Laboratory, Rochester, MN. We attribute our thanks to the Urologist in Department of Urology in Mayo Clinic Rochester, MN who provide the surgical videotape and clinic data for this study.

\section{Authors' contributions}

JZ analyzed data, and prepared manuscript draft. SK performed the experiments, analyzed data and prepared manuscript draft. MJ designed study, oversee the experimental analysis, and critically reviewed manuscript. SW and EW performed experiments during their summer research program and collect the related materials for manuscript. JCL designed study, supervised its completion and critically reviewed manuscript. All authors read and approved the final manuscript.

\section{Funding}

This study was supported by a pilot grant program from Mayo Clinic Rare Kidney Stone Consortium (U54DK083908) and Oxalosis \& Hyperoxaluria Foundation, and partly by the O'Brien Urology Research Center (U54 DK100227), Nephrology and Urology Summer Undergraduate Research Program (R25-DK101405), and Mayo Foundation. The authors were fully responsible for the collection, analysis, and interpretation of data and in writing the manuscript.

Availability of data and materials

The datasets used and/or analyzed during the current study are available from the corresponding author on reasonable request. 


\section{Declarations}

\section{Ethics approval and consent to participate}

This study was approved by the institutional review board at Mayo Clinic Rochester Minnesota, USA and written consent was obtained from study participants.

\section{Consent for publication}

Written consent was obtained from study participants to publish specific images and clinical details.

\section{Competing interests}

The authors declare no conflicts of interest or competing interests.

\section{Author details}

'Department of Urology, Beijing Chaoyang Hospital, Capital Medical University, No.8 Gongti Nanlu,Chaoyang District, 100020 Beijing, China. 2Department of Internal Medicine, Division of Nephrology and Hypertension, Mayo Clinic, 200 First Street SW, MN 55905 Rochester, USA. ${ }^{3}$ Department of Life Science, School of Basic Science and Research, Sharda University, Knowledge Park III, 201310, UP, Greater Noida, India. ${ }^{4}$ Department of Internal Medicine, Division of Hematology Research, Mayo Clinic, 55905 Rochester, MN, USA. ${ }^{5}$ Department of Physiology \& Biomedical Engineering, Mayo Clinic, 55905 Rochester, MN, USA. ${ }^{6}$ Department of Laboratory Medicine and Pathology, Mayo Clinic, 55905 Rochester, MN, USA.

Received: 26 August 2020 Accepted: 24 May 2021 Published online: 01 June 2021

\section{References}

1. Scales CD Jr, Smith AC, Hanley JM, Saigal CS. Urologic Diseases in America P: Prevalence of kidney stones in the United States. Eur Urol. 2012;62(1): $160-5$.

2. Khan SR, Canales BK. Unified theory on the pathogenesis of Randall's plaques and plugs. Urolithiasis. 2015;43(Suppl 1):109-23.

3. Sorokin I, Mamoulakis C, Miyazawa K, Rodgers A, Talati J, Lotan Y. Epidemiology of stone disease across the world. World J Urol. 2017;35(9): 1301-20.

4. Kustov AV, Strelnikov Al. Quantitative Mineralogical Composition of Calculi and Urine Abnormalities for Calcium Oxalate Stone Formers: A SingleCenter Results. Urol J. 2018;15(3):87-91.

5. Jayachandran M, Lugo G, Heiling H, Miller VM, Rule AD, Lieske JC Extracellular vesicles in urine of women with but not without kidney stones manifest patterns similar to men: a case control study. Biology of sex differences. 2015;6:2.

6. Fink HA, Wilt TJ, Eidman KE, Garimella PS, MacDonald R, Rutks IR, Brasure M, Kane RL, Ouellette J, Monga M. Medical management to prevent recurrent nephrolithiasis in adults: a systematic review for an American College of Physicians Clinical Guideline. Ann Intern Med. 2013;158(7):535-43.

7. Mulay SR, Anders HJ. Crystal nephropathies: mechanisms of crystal-induced kidney injury. Nature reviews Nephrology. 2017;13(4):226-40.

8. Evan AP, Lingeman JE, Worcester EM, Sommer AJ, Phillips CL, Williams JC, Coe FL. Contrasting histopathology and crystal deposits in kidneys of idiopathic stone formers who produce hydroxy apatite, brushite, or calcium oxalate stones. Anat Rec (Hoboken). 2014;297(4):731-48.

9. Evan AP, Lingeman JE, Coe FL, Parks JH, Bledsoe SB, Shao Y, Sommer AJ Paterson RF, Kuo RL, Grynpas M. Randall's plaque of patients with nephrolithiasis begins in basement membranes of thin loops of Henle. J Clin Invest. 2003;111(5):607-16.

10. Linnes MP, Krambeck AE, Cornell L, Williams JC Jr, Korinek M, Bergstralh EJ, Li X, Rule AD, McCollough CM, Vrtiska TJ, et al. Phenotypic characterization of kidney stone formers by endoscopic and histological quantification of intrarenal calcification. Kidney Int. 2013;84(4):818-25.

11. Kusmartsev S, Dominguez-Gutierrez PR, Canales BK, Bird VG, Vieweg J, Khan SR. Calcium Oxalate Stone Fragment and Crystal Phagocytosis by Human Macrophages. J Urol. 2016;195(4 Pt 1):1143-51

12. Mulay SR, Kulkarni OP, Rupanagudi KV, Migliorini A, Darisipudi MN, Vilaysane A, Muruve D, Shi Y, Munro F, Liapis H, et al. Calcium oxalate crystals induce renal inflammation by NLRP3-mediated IL-1ß secretion. J Clin Invest. 2013; 123(1):236-46
13. Singhto N, Kanlaya R, Nilnumkhum A, Thongboonkerd V. Roles of Macrophage Exosomes in Immune Response to Calcium Oxalate Monohydrate Crystals. Front Immunol. 2018;9:316.

14. Azoidis I, Cox SC, Davies OG. The role of extracellular vesicles in biomineralisation: current perspective and application in regenerative medicine. J Tissue Eng. 2018:9:2041731418810130.

15. Turco AE, Lam W, Rule AD, Denic A, Lieske JC, Miller VM, Larson JJ, Kremers WK, Jayachandran M. Specific renal parenchymal-derived urinary extracellular vesicles identify age-associated structural changes in living donor kidneys. J Extracell Vesicles. 2016;5:29642.

16. Chirackal RS, Jayachandran M, Wang X, Edeh S, Haskic Z, Perinpam M, Halling TM, Mehta R, Rivera ME, Lieske JC. Urinary extracellular vesicleassociated MCP-1 and NGAL derived from specific nephron segments differ between calcium oxalate stone formers and controls. American journal of physiology Renal physiology. 2019;317(6):F1475-f1482.

17. Hiemstra TF, Charles PD, Gracia T, Hester SS, Gatto L, Al-Lamki R, Floto RA, Su Y, Skepper JN, Lilley KS, et al. Human urinary exosomes as innate immune effectors. Journal of the American Society of Nephrology: JASN. 2014:25(9):2017-27.

18. Park J, Lin HY, Assaker JP, Jeong S, Huang CH, Kurdi T, Lee K, Fraser K, Min C, Eskandari S, et al. Integrated Kidney Exosome Analysis for the Detection of Kidney Transplant Rejection. ACS Nano. 2017;11(11):11041-6.

19. Chirackal RS, Jayachandran M, Wang X, Edeh S, Haskic Z, Perinpam M, Halling TM, Mehta R, Rivera ME, Lieske JC. Urinary extracellular vesicles associated MCP-1 and NGAL derived from specific nephron segments differ between calcium oxalate stone formers and controls. American journal of physiology Renal physiology 2019.

20. Low RK, Stoller ML. Endoscopic mapping of renal papillae for Randall's plaques in patients with urinary stone disease. J Urol. 1997;158(6):2062-4.

21. Wang $X$, Krambeck AE, Williams JC Jr, Tang X, Rule AD, Zhao F, Bergstralh E, Haskic Z, Edeh S, Holmes DR 3. Distinguishing characteristics of idiopathic calcium oxalate kidney stone formers with low amounts of Randall's plaque. Clin J Am Soc Nephrol. 2014;9(10):1757-63. rd et al.

22. Erdbrugger U, Le TH. Extracellular Vesicles in Renal Diseases: More than Novel Biomarkers? Journal of the American Society of Nephrology: JASN. 2016:27(1):12-26.

23. Coe FL, Parks JH, Asplin JR. The pathogenesis and treatment of kidney stones. N Engl J Med. 1992;327(16):1141-52.

24. Daudon M, Hennequin C, Boujelben G, Lacour B, Jungers P. Serial crystalluria determination and the risk of recurrence in calcium stone formers. Kidney Int. 2005;67(5):1934-43.

25. Schepers MS, Duim RA, Asselman M, Romijn JC, Schröder FH, Verkoelen CF. Internalization of calcium oxalate crystals by renal tubular cells: a nephron segment-specific process? Kidney Int. 2003;64(2):493-500.

26. Evan AP, Weinman EJ, Wu XR, Lingeman JE, Worcester EM, Coe FL. Comparison of the pathology of interstitial plaque in human ICSF stone patients to NHERF-1 and THP-null mice. Urol Res. 2010:38(6):439-52.

27. Okada A, Hamamoto S, Taguchi K, Unno R, Sugino T, Ando R, Mizuno K, Tozawa K, Kohri K, Yasui T. Kidney stone formers have more renal parenchymal crystals than non-stone formers, particularly in the papilla region. BMC Urol. 2018;18(1):19.

28. Andrade-Oliveira V, Foresto-Neto O, Watanabe IKM, Zatz R, Camara NOS Inflammation in Renal Diseases: New and Old Players. Front Pharmacol. 2019;10:1192.

29. Singhto $\mathrm{N}$, Thongboonkerd $\mathrm{V}$. Exosomes derived from calcium oxalateexposed macrophages enhance IL-8 production from renal cells, neutrophil migration and crystal invasion through extracellular matrix. Journal of proteomics. 2018;185:64-76.

30. Wen C, Seeger RC, Fabbri M, Wang L, Wayne AS, Jong AY. Biological roles and potential applications of immune cell-derived extracellular vesicles. Journal of extracellular vesicles. 2017;6(1):1400370

31. Quaglia M, Dellepiane S, Guglielmetti G, Merlotti G, Castellano G, Cantaluppi V. Extracellular Vesicles as Mediators of Cellular Crosstalk Between Immune System and Kidney Graft. Front Immunol. 2020;11:74.

32. Lugini L, Cecchetti S, Huber V, Luciani F, Macchia G, Spadaro F, Paris L, Abalsamo L, Colone M, Molinari A, et al. Immune surveillance properties of human NK cell-derived exosomes. Journal of immunology (Baltimore Md: 1950). 2012;189(6):2833-42

33. Cheng Y, Wang X, Yang J, Duan X, Yao Y, Shi X, Chen Z, Fan Z, Liu X, Qin S, et al. A translational study of urine miRNAs in acute myocardial infarction. J Mol Cell Cardiol. 2012;53(5):668-76. 
34. Golub EE. Role of matrix vesicles in biomineralization. Biochim Biophys Acta. 2009;1790(12):1592-8.

35. Hu MC, Shiizaki K, Kuro-o M, Moe OW. Fibroblast growth factor 23 and Klotho: physiology and pathophysiology of an endocrine network of mineral metabolism. Annu Rev Physiol. 2013;75:503-33.

36. Gattineni J, Alphonse P, Zhang Q, Mathews N, Bates CM, Baum M. Regulation of renal phosphate transport by FGF23 is mediated by FGFR1 and FGFR4. Am J Physiol Renal Physiol. 2014;306(3):F351-8.

37. Ide N, Olauson H, Sato T, Densmore MJ, Wang H, Hanai II, Larsson TE, Lanske B. In vivo evidence for a limited role of proximal tubular Klotho in renal phosphate handling. Kidney international. 2016;90(2):348-62

38. Grange C, Papadimitriou E, Dimuccio V, Pastorino C, Molina J, O'Kelly R, Niedernhofer $\sqcup$, Robbins PD, Camussi G, Bussolati B. Urinary Extracellular Vesicles Carrying Klotho Improve the Recovery of Renal Function in an Acute Tubular Injury Model. Mol Ther. 2020;28(2):490-502.

39. Lu X, Hu MC. Klotho/FGF23 Axis in Chronic Kidney Disease and Cardiovascular Disease. Kidney diseases (Basel Switzerland). 2017;3(1):15-23.

40. Raiborg C, Bache KG, Mehlum A, Stang E, Stenmark H. Hrs recruits clathrin to early endosomes. EMBO J. 2001;20(17):5008-21.

41. Legendre-Guillemin V, Metzler M, Lemaire JF, Philie J, Gan L, Hayden MR, McPherson PS. Huntingtin interacting protein 1 (HIP1) regulates clathrin assembly through direct binding to the regulatory region of the clathrin light chain. J Biol Chem. 2005;280(7):6101-8.

42. Suzuki J, Fujii T, Imao T, Ishihara K, Kuba H, Nagata S. Calcium-dependent phospholipid scramblase activity of TMEM16 protein family members. J Biol Chem. 2013;288(19):13305-16.

43. Whitlock JM, Hartzell HC. Anoctamins/TMEM16 Proteins: Chloride Channels Flirting with Lipids and Extracellular Vesicles. Annu Rev Physiol. 2017;79:11943.

44. Devarajan A. Cross-talk between renal lithogenesis and atherosclerosis: an unveiled link between kidney stone formation and cardiovascular diseases. Clin Sci (Lond). 2018;132(6):615-26.

\section{Publisher's Note}

Springer Nature remains neutral with regard to jurisdictional claims in published maps and institutional affiliations.

Ready to submit your research? Choose BMC and benefit from:

- fast, convenient online submission

- thorough peer review by experienced researchers in your field

- rapid publication on acceptance

- support for research data, including large and complex data types

- gold Open Access which fosters wider collaboration and increased citations

- maximum visibility for your research: over $100 \mathrm{M}$ website views per year

At $\mathrm{BMC}$, research is always in progress.

Learn more biomedcentral.com/submissions 